\title{
Dock3 attenuates neural cell death due to NMDA neurotoxicity and oxidative stress in a mouse model of normal tension glaucoma
}

\author{
K Namekata ${ }^{1}$, A Kimura ${ }^{1}$, K Kawamura ${ }^{1}$, X Guo ${ }^{1}$, C Harada ${ }^{1}$, K Tanaka $^{2}$ and T Harada ${ }^{*, 1}$
}

Dedicator of cytokinesis 3 (Dock3), a new member of the guanine nucleotide exchange factors for the small GTPase Rac1, promotes axon regeneration following optic nerve injury. In the present study, we found that Dock3 directly binds to the intracellular C-terminus domain of NR2B, an N-methyl-D-aspartate (NMDA) receptor subunit. In transgenic mice overexpressing Dock3 (Dock3 Tg), NR2B expression in the retina was significantly decreased and NMDA-induced retinal degeneration was ameliorated. In addition, overexpression of Dock3 protected retinal ganglion cells (RGCs) from oxidative stress. We previously reported that glutamate/aspartate transporter (GLAST) is a major glutamate transporter in the retina, and RGC degeneration due to glutamate neurotoxicity and oxidative stress is observed in GLAST-deficient (KO) mice. In GLAST KO mice, the NR2B phosphorylation rate in the retina was significantly higher compared with Dock3 Tg:GLAST KO mice. Consistently, glaucomatous retinal degeneration was significantly improved in GLAST KO:Dock3 Tg mice compared with GLAST KO mice. These results suggest that Dock3 overexpression prevents glaucomatous retinal degeneration by suppressing both NR2B-mediated glutamate neurotoxicity and oxidative stress, and identifies Dock3 signaling as a potential therapeutic target for both neuroprotection and axonal regeneration.

Cell Death and Differentiation (2013) 20, 1250-1256; doi:10.1038/cdd.2013.91; published online 12 July 2013

Excitatory neurotransmission mediated by $\mathrm{N}$-methyl-D-aspartate receptors (NMDARs), one of the ionotropic glutamate receptors, has fundamental roles in both physiological and pathological processes in the mammalian central nervous system (CNS). Overactivation of NMDA receptors is thought to be a key contributing factor in the pathophysiology of many CNS disorders, such as Alzheimer's disease ${ }^{1,2}$ and Huntington disease. ${ }^{3}$ Glutamate excitotoxicity is also implicated in the degeneration of the retinal ganglion cells (RGCs) and optic nerves observed under pathological conditions including glaucoma. ${ }^{4,5}$ Consistently, we previously reported that loss of glutamate/aspartate transporter (GLAST) induces optic neuropathy without affecting intraocular pressure and exhibits many features similar to human normal tension glaucoma. ${ }^{6}$

NMDA receptors are tetramers that form functional receptor channels. Two NR1 subunits, which bind its co-agonist glycine, must combine with at least two NR2 (A-D) subunits, which bind glutamate. ${ }^{7}$ In the retina, NMDARs on RGCs are activated by glutamate released from cone bipolar cells. ${ }^{8}$ All four NR2 subunits are expressed in vertebrate retina, and both NR2A and NR2B are prevalent in the inner plexiform layer, where NMDARs are localized on RGC dendrites. ${ }^{9-11}$ Among them, NR2B-containing receptors are shown to exhibit relatively high affinity both for glutamate and for the co-agonist glycine, prolonged channel opening and greater overall $\mathrm{Ca}^{2+}$ current per event. ${ }^{12,13}$ It is well known that the intracellular C-terminus domain (CTD) of NR2B regulates the internalization and degradation of NR2B-containing receptors. ${ }^{14-17}$ At postsynaptic sites, NR2B-CTD is phosphorylated at Tyr1472 by Fyn, thereby mediating complex formation of NMDA receptors with the postsynaptic density protein 95 (PSD95). This NMDAR-PSD95 interaction is required for excitotoxic downstream signaling. ${ }^{17}$ Functionally, NR2B has been implicated in many forms of synaptic plasticity related to the physiology of striatal neurons and the pathogenesis of various neurological disorders. ${ }^{18}$ Indeed, amyloid- $\beta(\mathrm{A} \beta)$ and tau protein promote Fyn-mediated NR2B stabilization at the plasma membrane, resulting in the enhancement of NMDAR-mediated neurodegeneration in the brain of a mouse model of Alzheimer's disease. ${ }^{1,2,19}$

Dedicator of cytokinesis 3 (Dock3), a new member of the guanine nucleotide exchange factors, is specifically expressed in neural cells and causes cellular morphological changes by activating the small GTPase Rac1. ${ }^{20}$ We previously reported that Dock3 is primarily expressed in RGCs in the retina, and that Dock3 overexpression stimulates axonal regeneration after optic nerve injury in vivo. ${ }^{21,22}$ Dock3 was initially identified as a binding protein to presenilin1,

\footnotetext{
${ }^{1}$ Visual Research Project, Tokyo Metropolitan Institute of Medical Science, Tokyo, Japan and ${ }^{2}$ Laboratory of Molecular Neuroscience, School of Biomedical Science and Medical Research Institute, Tokyo Medical and Dental University, Tokyo, Japan

*Corresponding author: T Harada, Visual Research Project, Tokyo Metropolitan Institute of Medical Science, 2-1-6 Kamikitazawa, Setagaya-ku, Tokyo 156-8506, Japan. Tel: + 8136834 2338; Fax: + 8136834 2339; E-mail: harada-tk@igakuken.or.jp Keywords: Dock3; glutamate; oxidative stress; neuroprotection; glaucoma

Abbreviations: A $\beta$, amyloid-beta; ASK1, apoptosis signal-regulating kinase 1; BDNF, brain-derived neurotrophic factor; CNS, central nervous system; CTD, intracellular C-terminus domain; Dock3, Dedicator of cytokinesis 3; GLAST, glutamate/aspartate transporter; GSK-3 $\beta$, glycogen synthase kinase-3 $\beta$; LDH, lactate dehydrogenase; NMDA, N-methyl-D-aspartate; PSD95, postsynaptic density protein 95; RGC, retinal ganglion cell

Received 01.4.13; revised 29.5.13; accepted 11.6.13; Edited by N Bazan; published online 12.7.13
} 
a major causative gene of early-onset familial Alzheimer's disease. ${ }^{23,24}$ Although the critical role of Dock3 in Alzheimer's disease is still unknown, it is reported that Dock3 is deposited and insolubilized in Alzheimer's disease brain. ${ }^{23,25}$ In addition, a recent study reported that Rac1 activation mediated by Dock1 (Dock180), a homolog protein of Dock3, regulates endocytic membrane trafficking. ${ }^{26}$ These observations suggest a possible interaction between Dock3 and NR2B, which may regulate NR2B expression in neural tissues. In addition, recent studies suggested a possibility that there is a causal relationship between Alzheimer's disease and glaucoma. ${ }^{27,28}$ These observations prompted us to examine the interaction

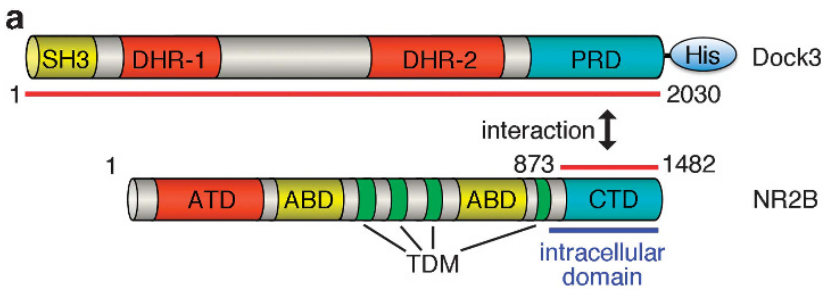

b
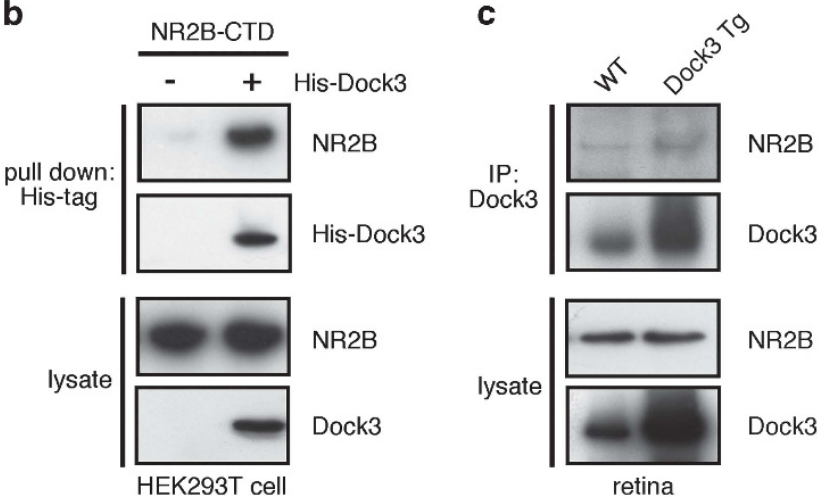

Figure 1 Dock3 interacts with the CTD of NR2B. (a) Schematic representation showing the His-tagged WT Dock3 and NR2B-CTD used in the pull-down assay. $\mathrm{SH} 3$, Src homology 3 domain; DHR-1, Dock homology region 1; DHR-2, dock homology region 2; PRD, proline-rich domain; ATD, amino-terminal domain; ABD, agonist binding domain; TDM, transmembrane domain; CTD, intracellular C-terminal domain. (b) Lysates from HEK293T cells transfected with His-tagged full-length Dock3 and NR2B-CTD were subjected to a His-tag pull-down assay. (c) Lysates from retinas of WT and Dock3 $\mathrm{Tg}$ mice were subjected to immunoprecipitation assay using an anti-Dock3 antibody between Dock3 and NR2B in the retina, and the effects of Dock3 on GLAST-deficient (GLAST KO) mice that suffer from glaucoma-like RGC degeneration. ${ }^{6}$

\section{Results}

Dock3 interacts with NR2B in the retina. We first examined whether Dock3 binds to NR2B in neural cells. For this experiment, we transfected His-tagged full-length Dock3 and CTD of NR2B (NR2B-CTD) (Figure 1a) to HEK293T cells and found that Dock3 binds to NR2B-CTD using His-tag pull-down assay (Figure 1b). We next examined whether Dock3 and NR2B are bound in neural tissues in vivo. The interaction between endogenous Dock3 and NR2B in wild-type (WT) mouse retina was confirmed by a co-immunoprecipitation assay (Figure 1c). We also found that the binding between Dock3 and NR2B was increased in Dock3 $\mathrm{Tg}$ mice, in which Dock3 is overexpressed in the retina (Figure 1c). ${ }^{21}$

We previously showed that Dock3 is abundantly expressed in retinal ganglion cells (RGCs) and stimulates axon outgrowth in adult mice. ${ }^{21,22}$ Double-labeling immunohistochemistry showed that NR2B immunoreactivity was co-localized with Dock3 mainly in the ganglion cell layer (GCL) (Figure 2). These data support the binding of Dock3 and NR2B in RGCs of the adult retina in vivo.

Dock3 increases NMDA-mediated NR2B degradation in the retina. NMDA receptors undergo endocytosis and lysosomal sorting for receptor degradation. ${ }^{14-18}$ As Dock3 and NR2B are bound in the retina, we investigated whether Dock3 affects NR2B degradation in the retina after NMDA stimulation. For this purpose, NR2B protein levels in the retinas from WT and Dock3 $\mathrm{Tg}$ mice were determined by immunoblot analysis at 3 and $24 \mathrm{~h}$ after the intraocular injection of phosphate-buffered saline (PBS; control) or NMDA. In the control retinas, NR2B expression levels in Dock3 Tg mice were not different compared with those in WT mice (Figure 3). NMDA injection had no effects on NR2B expression levels in the retina of WT mice, whereas NR2B expression levels were significantly decreased in Dock3 Tg mice (Figure 3). These results suggest that Dock3 enhances NR2B degradation due to glutamate neurotoxicity in the retina.
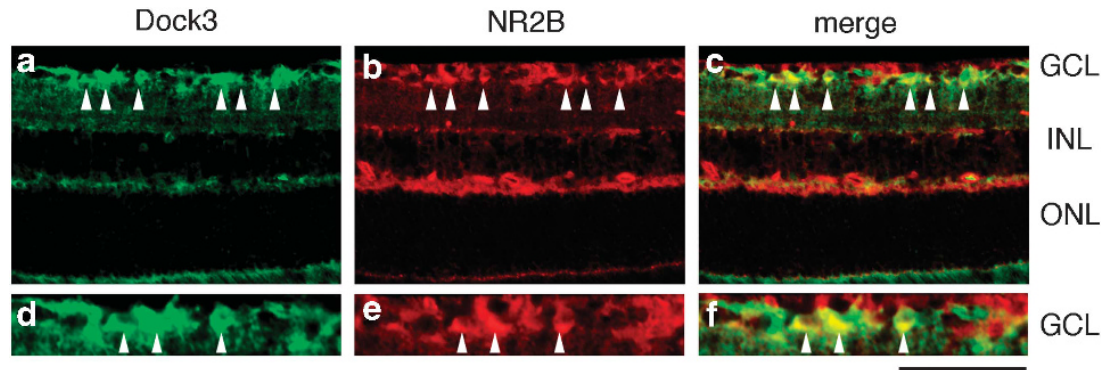

Figure 2 Expression of Dock3 and NR2B in the mouse retina. (a-c) Immunohistochemical analysis of mouse retina double-labeled (c) with antibodies against Dock3 (a) and NR2B (b). (d-f) Enlarged images of the GCL in $(\mathbf{a}-\mathbf{c})$, respectively. Arrow heads indicate double-labeled cells. GCL, ganglion cell layer; INL, inner nuclear layer; ONL, outer nuclear layer. Scale bar: $100 \mu \mathrm{m}(\mathrm{a}-\mathrm{c})$ and $50 \mu \mathrm{m}(\mathrm{d}-\mathbf{f})$ 


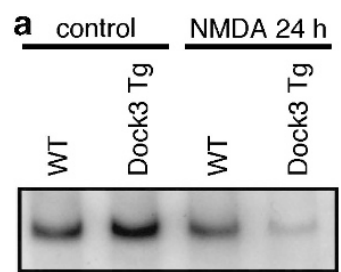

IB: NR2B

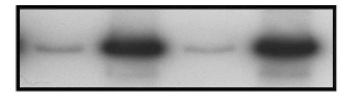

IB: Dock3

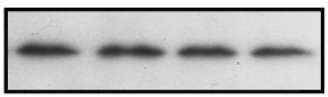

IB: actin

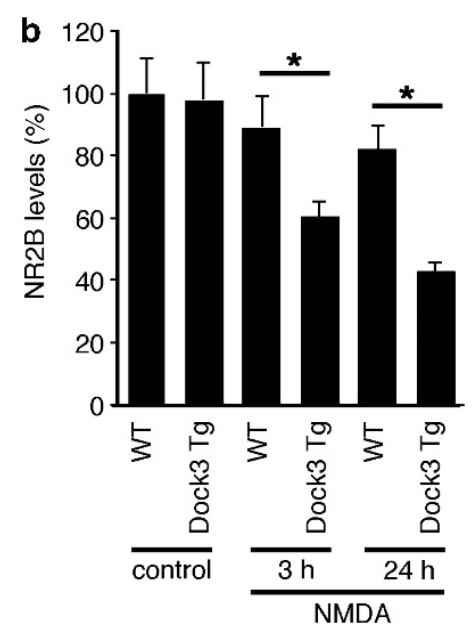

Figure 3 Effect of Dock3 on NR2B expression levels in the retina. (a) Immunoblot analysis of NR2B and Dock3 in the retinas of WT and Dock3 Tg mice $24 \mathrm{~h}$ after the injection of PBS (control) or NMDA. (b) Quantitative analysis of NR2B expression at 3 and $24 \mathrm{~h}$ after the injection of PBS (control) or NMDA. The data are presented as means \pm S.E.M. of six samples for each experiment ${ }^{*} P<0.05$

Dock3 overexpression protects retinal neurons from glutamate neurotoxicity. Our present results suggest that overexpression of Dock3 in the retina may ameliorate glutamate neurotoxicity via NR2B degradation. To determine this possibility, we examined the effect of intraocular injection of NMDA on retinal cell death in WT and Dock3 Tg mice. The retinal structure of adult Dock3 Tg mice was normal, and the cell number in the GCL $(497 \pm 26 ; n=6)$ was comparable to WT mice (488 $\pm 31 ; n=6$ ) (Figures $4 a$ and $b$ ). In addition, the thickness of the inner retinal layer (IRL, between the internal limiting membrane and the interface of the outer plexiform layer and the outer nuclear layer) was similar in both strains (Figure 4c). Intraocular administration of NMDA induced cell death in the GCL in both WT and Dock3 Tg mice, but the number of surviving neurons in Dock3 $\mathrm{Tg}$ mice was significantly higher than that in WT mice at 5 and 7 days after NMDA injection (Figures $4 a$ and b). Additionally, IRL thickness in Dock3 Tg mice was significantly increased at 7 days after NMDA injection compared with that in WT mice (Figure 4c). These results suggest that Dock3 overexpression prevents retinal cell death from glutamate neurotoxicity in vivo.

Dock3 overexpression protects RGCs from oxidative stress. Our previous study showed that oxidative stress, as well as glutamate neurotoxicity, induces RGC death. ${ }^{29}$ To assess whether Dock3 also prevents oxidative stressinduced RGC death, cultured RGCs from WT mice were transfected with myc-tagged Dock3 plasmid by electroporation, and hydrogen peroxide $\left(\mathrm{H}_{2} \mathrm{O}_{2}\right)$-induced $\mathrm{RGC}$ death was assessed through the lactate dehydrogenase( $\mathrm{LDH})$ leakage assays. Immunoblot analysis demonstrated that electroporation increased Dock3 expression levels in cultured RGCs (Figure 5a). The LDH leakage assay revealed that $\mathrm{H}_{2} \mathrm{O}_{2}$ induced cell death was significantly reduced in RGCs transfected with Dock3 plasmid compared with mock plasmid (Figures $5 b$ and $c$ ). These results suggest that Dock3 a
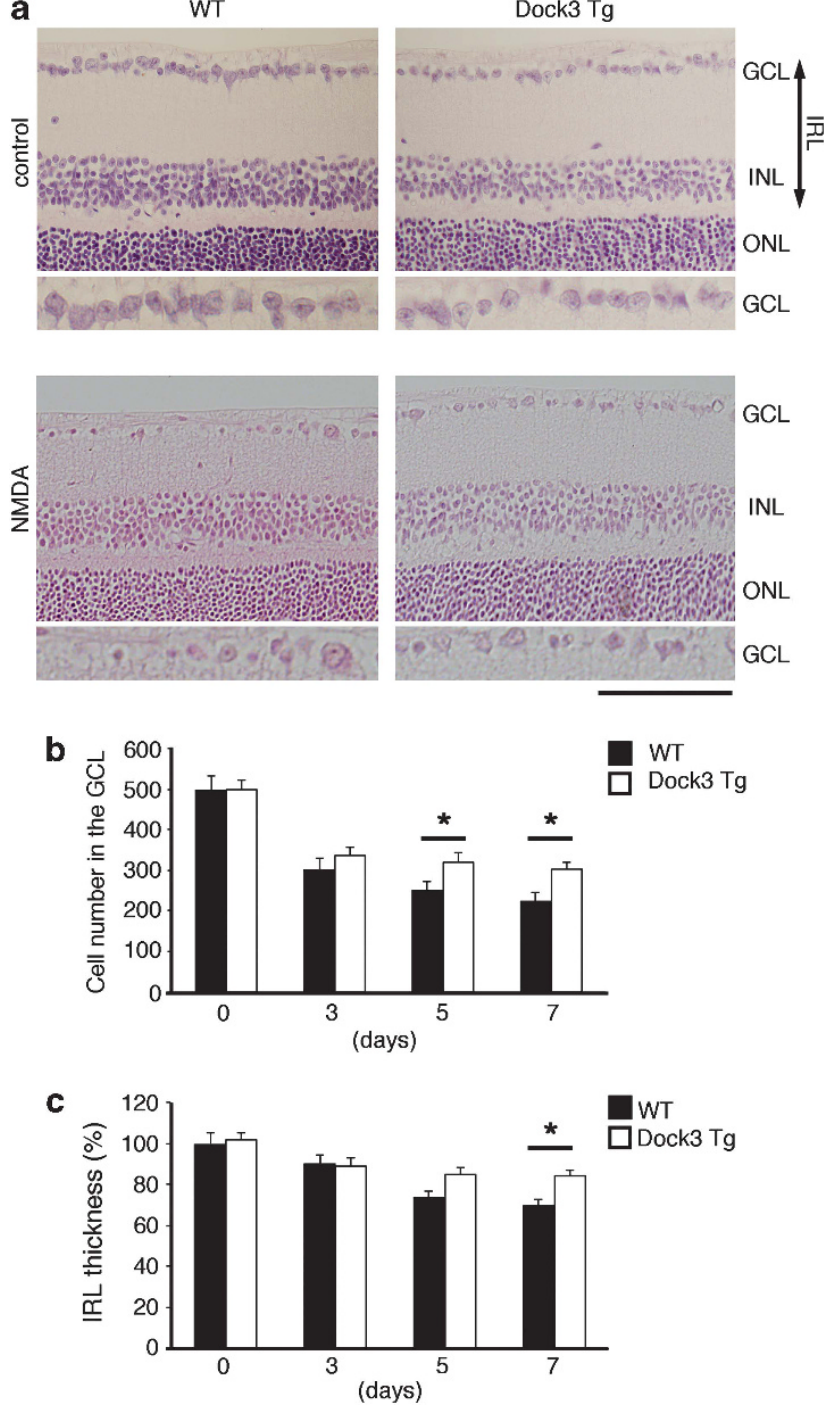

Figure 4 Dock3 protects retinal neurons from glutamate neurotoxicity. (a) H\&E staining of retinal sections in WT and Dock3 Tg mice 7 days after intraocular treatment of PBS (control) or NMDA. Scale bar: $100 \mu \mathrm{m}$ and $50 \mu \mathrm{m}$ in the upper and lower panels, respectively. GCL, ganglion cell layer; INL, inner nuclear layer; ONL, outer nuclear layer. (b and c) Quantification of cell number in the GCL (b) and thickness of the inner retinal layer (c) at 0, 3, 5 and 7 days after NMDA treatment. The data are presented as means \pm S.E.M. of six samples for each experiment ${ }^{\star} P<0.05$

overexpression protects RGCs from both glutamate neurotoxicity and oxidative stress.

Dock3 overexpression prevents glaucomatous retinal degeneration. We previously reported that glutamate neurotoxicity and oxidative stress are involved in RGC degeneration in GLAST KO mice, which is a mouse model of normal tension glaucoma. ${ }^{6}$ In 3-month-old GLAST KO mice, the cell number in the GCL $(325 \pm 10 ; n=6)$ was significantly reduced compared with that in WT $(479 \pm 23$; $n=6)$ and Dock3 $\operatorname{Tg}(488 \pm 21 ; n=6)$ mice (Figures $6 a$ and b). Consistently, the thickness of the IRL was significantly reduced in GLAST KO mice compared with WT and Dock3 Tg mice (Figure 6c). As Dock3 may inhibit the two main 

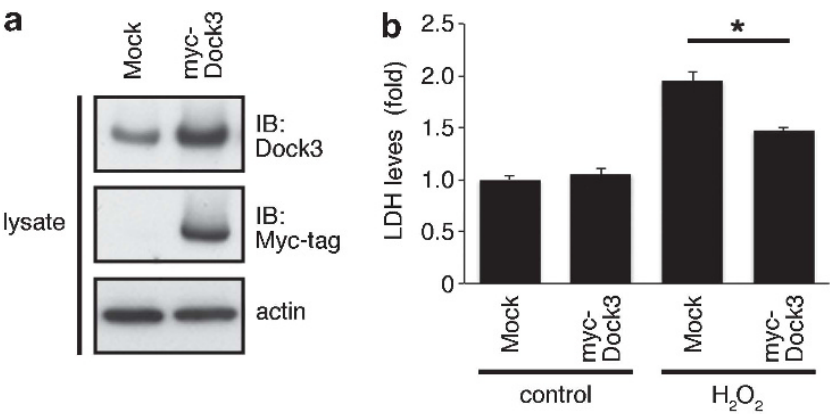

C

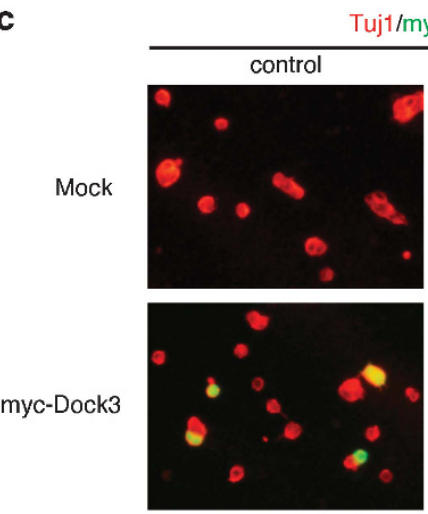

Tuj1/myc-Dock3

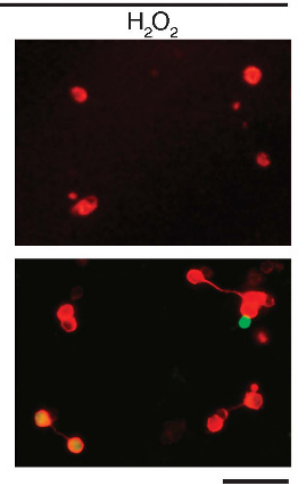

Figure 5 Effect of Dock3 on $\mathrm{H}_{2} \mathrm{O}_{2}$-induced $\mathrm{RGC}$ death in vitro. (a) Lysates from cultured RGCs transfected with empty vector (Mock) or myc-tagged Dock3 plasmids were subjected to immunoblot analysis using anti-Dock3 and anti-myc antibodies. (b) Cultured RGCs were stimulated with $\mathrm{H}_{2} \mathrm{O}_{2}$ for $16 \mathrm{~h}$, and the extent of $\mathrm{RGC}$ death was quantified by examining extracellular LDH activities. Note the decrease in $\mathrm{H}_{2} \mathrm{O}_{2}$-induced death in RGCs transfected with Dock3. (c) Pictures of cultured RGCs before and $16 \mathrm{~h}$ after stimulation with $\mathrm{H}_{2} \mathrm{O}_{2}$. The data are presented as means \pm S.E.M. of six samples for each experiment ${ }^{*} P<0.05$

causes of retinal degeneration in GLAST KO mice, we generated Dock3 Tg:GLAST KO mice and examined the histopathology of the retina (Figure 6a). In 3-month-old Dock3 Tg:GLAST KO mice, cell number in the GCL $(427 \pm 26 ; n=6)$ and IRL thickness were significantly increased compared with those of GLAST KO mice (Figures 6b and c). We next examined total and phosphorylated (at pTyr1472) NR2B protein expressions in these mice. The ratio of phosphorylated/total NR2B in GLAST KO mice was significantly increased compared with that in WT mice, but such an increase was not detected in Dock3 Tg:GLAST KO mice (Figure 7). These results suggest that Dock3 overexpression prevents glaucomatous retinal degeneration in GLAST KO mice by suppressing both NR2Bmediated glutamate neurotoxicity and oxidative stress.

\section{Discussion}

Here we show that Dock3 directly binds to NR2B and stimulates NMDA-induced NR2B degradation in mouse retina, resulting in the protection of RGCs from excitotoxicity. We previously reported glaucomatous retinal degeneration due to glutamate neurotoxicity and oxidative stress in GLAST $\mathrm{KO}$ mice, the first animal model of normal tension glaucoma. ${ }^{6,30}$ By generating Dock3 Tg:GLAST KO mice, we a

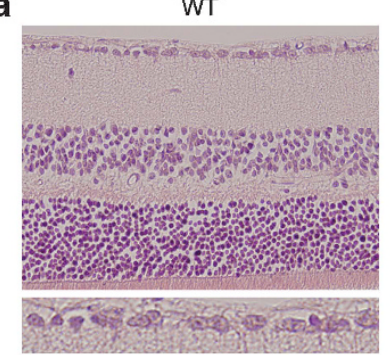

GLAST KO
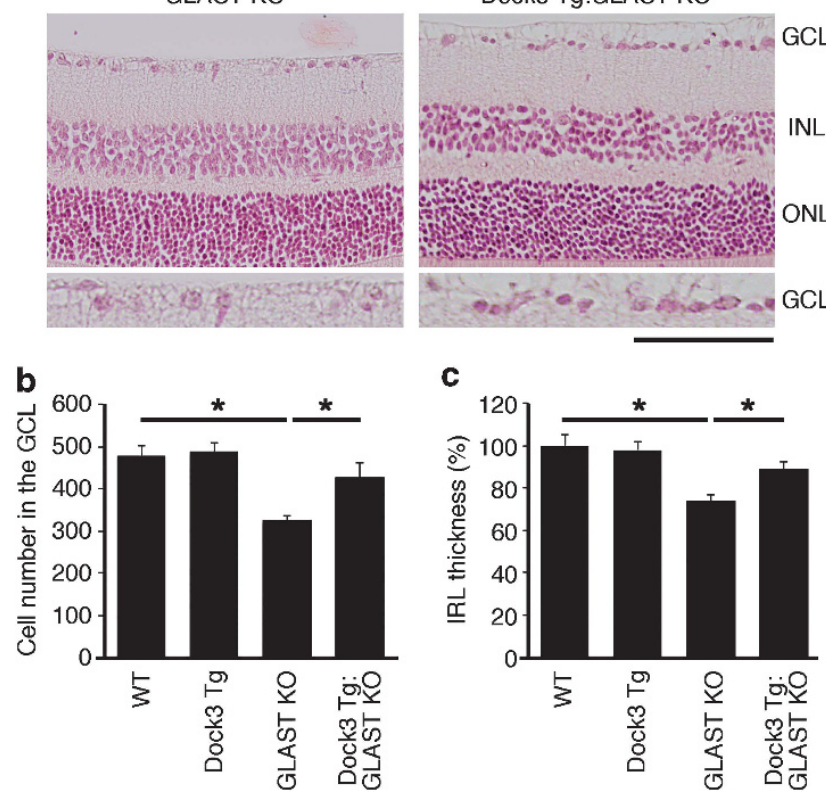

Figure 6 Effect of Dock3 on retinal degeneration in a mouse model of glaucoma. (a) H\&E staining of retinal sections of WT, Dock3 Tg, GLAST KO and Dock3 Tg:GLAST KO mice at 3 months. WT and Dock3 Tg mice were littermates. GLAST KO and Dock3 Tg:GLAST KO mice were littermates. Scale bar: $100 \mu \mathrm{m}$ and $50 \mu \mathrm{m}$ in the upper and lower rows, respectively. GCL, ganglion cell layer; INL, inner nuclear layer; ONL, outer nuclear layer. (b and $\mathbf{c}$ ) Quantification of cell number in the GCL (b) and thickness of the inner retinal layer (c) in WT, Dock3 Tg, GLAST KO and Dock3 Tg:GLAST KO mice. The data are presented as means \pm S.E.M. of six samples for each experiment ${ }^{*} P<0.05$

confirmed the neuroprotective effect of Dock3 in vivo. NR2B activation was increased in GLAST KO mice, but significantly suppressed in Dock3 Tg:GLAST KO mice. These results suggest that Dock3 exerts neuroprotective effects by regulating the activity of NR2B. It has been reported that GLAST (EAAT1 in humans) is downregulated in the retinas of human patients with glaucoma ${ }^{31}$ and in fibroblasts from patients with Alzheimer's disease. ${ }^{32}$ In addition, the accumulation of $A \beta$ is also observed in apoptotic RGCs in a rat model of glaucoma. ${ }^{27}$ Considering the high frequency of glaucoma in Alzheimer's disease patients, ${ }^{28}$ common mechanisms such as GLAST dysfunction might contribute to both diseases. Taken together, these findings suggest that Dock3 overexpression may be a potential therapeutic target in treating various neurodegenerative disorders, including Alzheimer's disease and glaucoma. ${ }^{21,22,33}$ Further studies are required to reveal the mechanism of NMDA-induced degradation of NR2B receptors, which may be caused by calpain and the ubiquitin-proteasome system. ${ }^{34-37}$ 
a

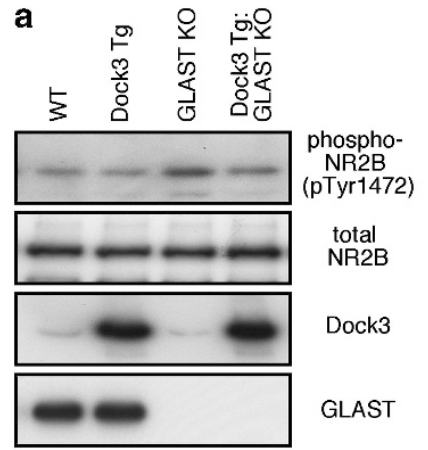

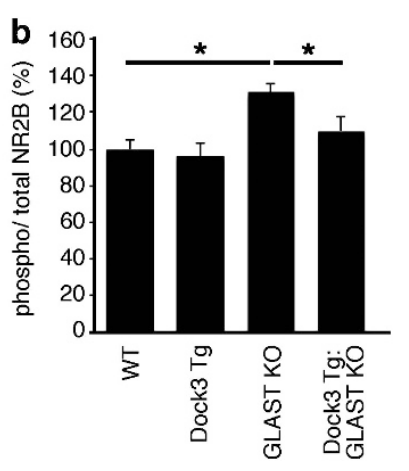

Figure 7 Effect of Dock3 on NR2B phosphorylation in a mouse model of glaucoma. (a) Immunoblot analysis of phosphorylated NR2B, total NR2B, Dock3 and GLAST in the retinas of WT, Dock3 Tg, GLAST KO and Dock3 Tg:GLAST KO mice. (b) Phosphorylation rate of NR2B in (a). The data are presented as means \pm S.E.M. of six samples for each experiment ${ }^{*} P<0.05$

In addition to glutamate neurotoxicity, oxidative stress is recognized as a common pathologic pathway in many neurodegenerative diseases, including glaucoma. ${ }^{38}$ For example, the reduction in glutathione, a major antioxidant in the retina, was reported in the plasma of human glaucoma patients. ${ }^{39} \mathrm{~A}$ similar reduction in glutathione concentration and increased oxidative stress were detected in GLAST KO mice. ${ }^{6}$ We previously reported that apoptosis signal-regulating kinase 1 (ASK1), a member of mitogen-activated protein 3 kinase, is involved in RGC loss in GLAST KO mice. ${ }^{30}$ ASK1 has key roles in human diseases closely related to the dysfunction of cellular responses to oxidative stress and endoplasmic reticulum stressors. ${ }^{40,41}$ As Dock3 protects RGCs from oxidative stress, the combination of Dock3 overexpression and inhibition of ASK1 signaling by a specific inhibitor $^{42}$ may be further available for the management of glaucoma. One important point is that glaucoma is a complex disease resulting from the confluence of various factors. ${ }^{27-32,43,44}$ To fill the gap between glaucoma patients and animal disease models, ${ }^{45}$ we are currently investigating GLAST gene abnormalities in glaucoma patients.

We previously showed that Dock3 has important roles downstream of brain-derived neurotrophic factor (BDNF) signaling in the CNS, where it promotes axonal outgrowth by stimulating microtubule assembly through glycogen synthase kinase-3 $\beta$ (GSK-3 $\beta) .{ }^{22}$ In addition to stimulating the outgrowth of optic nerve axons, BDNF protects RGCs after retinal and optic nerve injury. ${ }^{46-48}$ Interestingly, GSK-3 $\beta$ is a target for lithium-induced neuroprotection against excitotoxicity in neuronal cultures and animal models of ischemic stroke..$^{49}$ GSK-3 $\beta$ activity has been associated with many psychiatric and neurodegenerative diseases, and it has become increasingly apparent that GSK-3 $\beta$ might be a common therapeutic target for different classes of psychiatric drugs. ${ }^{50}$ Thus, Dock3 and GSK-3 $\beta$ could be potential targets for both neuroprotection and regeneration therapy. In the retina, there seems to be some cells that are positive for NR2B, but not Dock3 (Figure 2). This may mean that Dock3 decreases NR2B expression mainly in RGCs in normal retina, but overexpression of Dock3 in the whole retina may protect many types of retinal neurons. In addition, Dock3 expression in cells other than RGCs may have important roles for RGC protection and optic nerve regeneration in Dock3 Tg mice. For example, microglia that invade the inner retina during degeneration may release several trophic factors including BDNF, which stimulate neuroprotection. ${ }^{51,52}$

It has been estimated that glaucoma will affect more than 80 million individuals worldwide by 2020 , with at least $6-8$ million individuals becoming bilaterally blind. ${ }^{53}$ Glaucoma is also the leading global cause of irreversible blindness, and is perhaps the most prevalent of all neurodegenerative diseases. ${ }^{4,54}$ Although further in vivo studies are required, our findings raise intriguing possibilities for the management of glaucoma by Dock3 overexpression in combination with trophic factors, ASK1 inhibitors, GLAST overexpression and so on. We are currently investigating this possibility by using Dock3 virus vectors and GLAST Tg mice.

\section{Materials and Methods}

Cell culture and pull-down assay. His-tagged full-length Dock3 ${ }^{20}$ and the CTD of NR2B (NR2B-CTD) ${ }^{15}$ were cotransfected to HEK293T cells using Lipofectamine Plus (Invitrogen, Carlsbad, CA, USA) according to the manufacturer's instructions. After $24 \mathrm{~h}$ of transfection, the cell lysate was incubated with TALON resin (TAKARA, Shiga, Japan) for $20 \mathrm{~min}$ at $4{ }^{\circ} \mathrm{C}$ with gentle agitation. ${ }^{20}$ After being washed, precipitated samples were separated on sodium dodecyl sulfate-polyacrylamide gels and subsequently electrotransferred to an Immobilon$P$ filter (Merck Millipore, Billerica, MA, USA). Membranes were incubated with antibodies against Dock3 (1:1000), ${ }^{21}$ myc-tag (1:1000; Santa Cruz Biotechnology, Santa Cruz, CA, USA), NR2B (1:1000; BD Biosciences, San Diego, CA, USA) or actin (1:1000; BD Biosciences). Dock3 antibody was originally reported as an antibody against the modifier of cell adhesion protein. ${ }^{20}$ Primary antibody binding was detected using horseradish peroxidase-labeled anti-mouse IgG secondary antibody (GE Health Care, Piscataway, NJ, USA) and visualized using the ECL Plus Western Blotting System (GE Health Care).

Mice. Experiments were performed using Dock3 $\mathrm{Tg}^{21,22}$ GLAST KO ${ }^{6,30}$ and Dock3 Tg:GLAST KO mice in accordance with the Tokyo Metropolitan Institute for Neuroscience Guidelines for the Care and Use of Animals. C57BL/6J mice were obtained from CLEA Japan (Tokyo, Japan). Intraocular injection of NMDA (Wako, Osaka, Japan) or PBS was achieved essentially as previously described. ${ }^{55}$ Briefly, a single $2-\mu \mathrm{l}$ injection of $1 \mathrm{mM}$ NMDA in $0.1 \mathrm{M}$ PBS (pH 7.4) was administered intravitreally into the right eye of each mouse, thereby delivering a dose of $2 \mathrm{nmol}$ of NMDA. The same volume of PBS was administered to the contralateral (left) eye as control. Animals were killed at $3 \mathrm{~h}$ and 1, 3, 5 and 7 days after NMDA injection.

Immunoprecipitation of the retina. The Dock3-NR2B complex was purified from the retina $(1 \mathrm{mg})$ of WT and Dock3 $\mathrm{Tg}$ mice by immunoprecipitation with anti-Dock3 antibody $(1: 200)$. The immunoprecipitates were subjected to an immunoblot analysis with an antibody against Dock3 $(1: 1000)$ or NR2B $(1: 1000)$. Immunoblotting of retinas from WT, Dock3 Tg, GLAST KO and Dock3 Tg:GLAST KO were performed as reported previously. ${ }^{55}$ Membranes were incubated with an antibody against NR2B $(1: 1000)$, phospho-NR2B at Tyr1472 (1:1000; BD Biosciences), Dock3 $(1: 1000)$, GLAST $(1: 1000)^{56}$ or actin $(1: 1000)$.

Histological and morphometric studies. Paraffin-embedded retinal sections of $7 \mu \mathrm{m}$ thickness were cut through the optic nerve and stained with hematoxylin and eosin (H\&E). The extent of retinal degeneration was quantified in two ways. ${ }^{52}$ First, the number of neurons in the GCL was counted from one ora serrata through the optic nerve to the other ora serrata. Second, in the same sections, thickness of the IRL (between the internal limiting membrane and the interface of the outer plexiform layer and the outer nuclear layer) was analyzed. Frozen retinal sections of $12 \mu \mathrm{m}$ thickness were incubated using anti-Dock3 $(1: 200)$ and anti-NR2B $(1: 100)$ antibodies. Cy-3-conjugated goat anti-rabbit IgG (Jackson ImmunoResearch, West Grove, PA, USA) and Cy-2-conjugated donkey anti-mouse IgG (Jackson ImmunoResearch) were used as secondary antibodies. Sections were examined by fluorescence microscopy (BX51; Olympus, Tokyo, 
Japan) equipped with Plan Fluor objectives and connected to a DP70 camera (Olympus).

Assessment of $\mathrm{H}_{2} \mathrm{O}_{2}$-induced cell death in cultured RGCs. Primary culture of mouse RGCs was prepared according to Barres et al. ${ }^{57}$ with minor modifications. ${ }^{29}$ Primary cultured RGCs were transfected with a myc-tagged Dock3 plasmid by electroporation using the Amaxa Nucleofector Device (program 0-005) with mouse neuron Nucleofector Kit (Amaxa Biosystems, Koeln, Germany). After 2 days, they were stimulated with $200 \mu \mathrm{M}$ of $\mathrm{H}_{2} \mathrm{O}_{2}$ for $16 \mathrm{~h}$ and the RGC death rate was analyzed using an LDH cytotoxic test kit (Wako) as previously reported. ${ }^{29}$ For immunocytochemistry, RGCs were stained with antibodies against Tuj1 (1:1000; R\&D, Minneapolis, MN, USA) and myc-tag (1: 1000; MBL, Nagoya, Japan).

Statistics. For statistical comparison of two samples, we used a two-tailed Student's $t$-test. Data are presented as means \pm S.E.M. $P<0.05$ was regarded as statistically significant.

\section{Conflict of Interest}

The authors declare no conflict of interest.

Acknowledgements. This study was supported by the Ministry of Education, Culture, Sports, Science and Technology of Japan (KN, AK, XG, CH, KT), the Takeda Science Foundation (KN) and the Funding Program for Next Generation World-Leading Researchers (NEXT Program) (TH).

1. Christie MJ, Napier IA, Eckert A, Staufenbiel M, Hardeman E, Götz J. Dendritic function of tau mediates amyloid- $\beta$ toxicity in Alzheimer's disease mouse models. Cell 2010; 142 387-397.

2. Shankar GM, Bloodgood BL, Townsend M, Walsh DM, Selkoe DJ, Sabatini BL. Natural oligomers of the Alzheimer amyloid- $\beta$ protein induce reversible synapse loss by modulating an NMDA-type glutamate receptor-dependent signaling pathway. J Neurosci 2007; 27 2866-2875.

3. Milnerwood AJ, Gladding CM, Pouladi MA, Kaufman AM, Hines RM, Boyd JD et al. Early increase in extrasynaptic NMDA receptor signaling and expression contributes to phenotype onset in Huntington's disease mice. Neuron 2010; 65: 178-190.

4. Zhang K, Zhang L, Weinerb RN. Ophthalmic drug discovery: novel targets and mechanisms for retinal diseases and glaucoma. Nat Rev Drug Discov 2012; 11: 541-559.

5. Skolnick P, Popik P, Trullas R. Glutamate-based antidepressants: 20 years on. Trends Pharmacol Sci 2009; 30: 563-569.

6. Harada T, Harada C, Nakamura K, Quah HM, Okumura A, Namekata K et al. The potential role of glutamate transporters in the pathogenesis of normal tension glaucoma. J Clin Invest 2007; 117: 1763-1770.

7. Paoletti $\mathrm{P}$, Bellone $\mathrm{C}$, Zhou $\mathrm{Q}$. NMDA receptor subunit diversity: impact on receptor properties, synaptic plasticity and disease. Nat Rev Neurosci 2013; 14: 383-400.

8. Kalbaugh TL, Zhang J, Diamond JS. Coagonist release modulates NMDA receptor subtype contributions at synaptic inputs to retinal ganglion cells. J Neurosci 2009; 29 1469-1479.

9. Brandstätter JH, Hartveit E, Sassoè-Pognetto M, Wässle H. Expression of NMDA and high-affinity kainate receptor subunit mRNAs in the adult rat retina. Eur J Neurosci 1994; 6 . 1100-1112.

10. Watanabe M, Mishina M, Inoue Y. Differential distributions of the NMDA receptor channel subunit mRNAs in the mouse retina. Brain Res 1994; 634: 328-332.

11. Gründer T, Kohler K, Kaletta A, Guenther E. The distribution and developmental regulation of NMDA receptor subunit proteins in the outer and inner retina of the rat. J Neurobiol 2000; 44: 333-342.

12. Sobczyk A, Scheuss V, Svoboda K. NMDA receptor subunit-dependent [Ca2 + ] signaling in individual hippocampal dendritic spines. J Neurosci 2005 29; 25: 6037-6046.

13. Yashiro K, Philpot BD. Regulation of NMDA receptor subunit expression and its implications for LTD, LTP, and metaplasticity. Neuropharmacology 2008; 55: 1081-1094.

14. Roche KW, Standley S, McCallum J, Dune LyC, Ehlers MD, Wenthold RJ. Molecular determinants of NMDA receptor internalization. Nat Neurosci 2001; 4: 794-802.

15. Nakazawa $T$, Komai S, Tezuka $T$, Hisatsune $C$, Umemori $H$, Semba $K$ et al Characterization of Fyn-mediated tyrosine phosphorylation sites on GluR12 (NR2B) subunit of the N-methyl-D-aspartate receptor. J Biol Chem 2001; 276: 693-699.

16. Rong Y, Lu X, Bernard A, Khrestchatisky M, Baudry M. Tyrosine phosphorylation of ionotropic glutamate receptors by Fyn or Src differentially modulates their susceptibility to calpain and enhances their binding to spectrin and PSD-95. J Neurochem 2001; 79: 382-390.

17. Salter MW, Kalia LV. Src kinases: a hub for NMDA receptor regulation. Nat Rev Neurosc 2004; 5: 317-328.
18. Loftis JM, Janowsky A. The N-methyl-D-aspartate receptor subunit NR2B: localization, functional properties, regulation, and clinical implications. Pharmacol Ther 2003; 97: 55-85.

19. Um JW, Nygaard HB, Heiss JK, Kostylev MA, Stagi M, Vortmeyer A et al. Alzheimer amyloid- $\beta$ oligomer bound to postsynaptic prion protein activates Fyn to impair neurons. Nat Neurosci 2012; 15: 1227-1235.

20. Namekata K, Enokido Y, Iwasawa K, Kimura H. MOCA induces membrane spreading by activating Rac1. J Biol Chem 2004; 279: 14331-14337.

21. Namekata K, Harada C, Taya C, Guo X, Kimura H, Parada LF et al. Dock3 induces axonal outgrowth by stimulating membrane recruitment of the WAVE complex. Proc Natl Acad Sci USA 2010; 107: 7586-7591.

22. Namekata K, Harada C, Guo X, Kimura A, Kittaka D, Watanabe $\mathrm{H}$ et al. Dock3 stimulates axonal outgrowth via GSK-3 $\beta$-mediated microtubule assembly. J Neurosci 2012; 32: 264-274

23. Kashiwa A, Yoshida $H$, Lee S, Paladino $T$, Liu $Y$, Chen $Q$ et al. Isolation and characterization of novel presenilin binding protein. J Neurochem 2000; 75 : 109-116.

24. Bertram L, Lill CM, Tanzi RE. The genetics of Alzheimer disease: back to the future. Neuron 2010; 68: 270-281.

25. Chen $Q$, Yoshida H, Schubert D, Maher P, Mallory M, Masliah E. Presenilin binding protein is associated with neurofibrillary alterations in Alzheimer's disease and stimulates tau phosphorylation. Am J Pathol 2001; 159: 1597-1602.

26. Sun L, Liu O, Desai J, Karbassi F, Sylvain MA, Shi A et al. CED-10/Rac1 regulates endocytic recycling through the RAB-5 GAP TBC-2. PLoS Genet 2012; 8: e1002785.

27. Guo L, Salt TE, Luong V, Wood N, Cheung W, Maass A et al. Targeting amyloid- $\beta$ in glaucoma treatment. Proc Natl Acad Sci USA 2007; 104: 13444-13449.

28. Tamura H, Kawakami H, Kanamoto T, Kato T, Yokoyama T, Sasaki K et al. High frequency of open-angle glaucoma in Japanese patients with Alzheimer's disease. J Neurol Sci 2006; 246: 79-83.

29. Harada C, Nakamura K, Namekata K, Okumura A, Mitamura Y, lizuka Y et al. Role of apoptosis signal-regulating kinase 1 in stress-induced neural cell apoptosis in vivo. Am J Pathol 2006; 168: 261-269.

30. Harada C, Namekata K, Guo X, Yoshida H, Mitamura Y, Matsumoto Y et al. ASK1 deficiency attenuates neural cell death in GLAST-deficient mice, a model of normal tension glaucoma. Cell Death Differ 2010; 17: 1751-1759.

31. Naskar R, Vorwerk CK, Dreyer EB. Concurrent downregulation of a glutamate transporter and receptor in glaucoma. Invest Ophthalmol Vis Sci 2000; 41: 1940-1944.

32. Zoia CP, Tagliabue E, Isella V, Begni B, Fumagalli L, Brighina L et al. Fibroblast glutamate transport in aging and in AD: correlations with disease severity. Neurobiol Aging 2005; 26 : 825-832

33. Bai N, Hayashi H, Aida T, Namekata $\mathrm{K}$, Harada T, Mishina M et al. Dock3 interaction with a glutamate-receptor NR2D subunit protects neurons from excitotoxicity. Mol Brain 2013; 6: 22.

34. Hawasli AH, Benavides DR, Nguyen C, Kansy JW, Hayashi K, Chambon P et al. Cyclin-dependent kinase 5 governs learning and synaptic plasticity via control of NMDAR degradation. Nat Neurosci 2007; 10: 880-886.

35. Wu HY, Hsu FC, Gleichman AJ, Baconguis I, Coulter DA, Lynch DR. Fyn-mediated phosphorylation of NR2B Tyr-1336 controls calpain-mediated NR2B cleavage in neurons and heterologous systems. J Biol Chem 2007; 2822007 5-20087.

36. Mao LM, Wang W, Chu XP, Zhang GC, Liu XY, Yang YJ et al. Stability of surface NMDA receptors controls synaptic and behavioral adaptations to amphetamine. Nat Neurosci 2009; 12: 602-610.

37. Kurup $\mathrm{P}$, Zhang $\mathrm{Y}, \mathrm{Xu}$ J, Venkitaramani DV, Haroutunian V, Greengard $\mathrm{P}$ et al. A $\beta$-mediated NMDA receptor endocytosis in Alzheimer's disease involves ubiquitination of the tyrosine phosphatase STEP61. J Neurosci 2010; 30: 5948-5957.

38. Osborne NN, del Olmo-Aguado S. Maintenance of retinal ganglion cell mitochondrial functions as a neuroprotective strategy in glaucoma. Curr Opin Pharmacol 2013; 13 : 16-22.

39. Gherghel D, Griffiths HR, Hilton EJ, Cunliffe IA, Hosking SL. Systemic reduction in glutathione levels occurs in patients with primary open-angle glaucoma. Invest Ophthalmol Vis Sci 2005; 46: 877-883.

40. Nishitoh H, Kadowaki H, Nagai A, Maruyama T, Yokota T, Fukutomi H et al. ALS-linked mutant SOD1 induces ER stress- and ASK1-dependent motor neuron death by targeting Derlin-1. Genes Dev 2008; 22: 1451-1464.

41. Hattori K, Naguro I, Runchel C, Ichijo $\mathrm{H}$. The roles of ASK family proteins in stress responses and diseases. Cell Commun Signal 2009; 7: 9.

42. Guo X, Harada C, Namekata K, Matsuzawa A, Camps M, Ji H et al. Regulation of the severity of neuroinflammation and demyelination by TLR-ASK1-p38 pathway. EMBO MO Med 2010; 2: 504-515.

43. Boland MV, Ervin AM, Friedman DS, Jampel HD, Hawkins BS, Vollenweider D et al. Comparative effectiveness of treatments for open-angle glaucoma: a systematic review for the U.S. Preventive Services Task Force. Ann Intern Med 2013; 158: 271-279.

44. Hollands H, Johnson D, Hollands S, Simel DL, Jinapriya D, Sharma S. Do findings on routine examination identify patients at risk for primary open-angle glaucoma? The rational clinical examination systematic review. JAMA 2013; 309: 2035-2042.

45. Bouhenni RA, Dunmire J, Sewell A, Edward DP. Animal models of glaucoma. J Biomed Biotechnol 2012; 2012: 692609. 
46. Harvey AR, Hellström M, Rodger J. Gene therapy and transplantation in the retinofugal pathway. Prog Brain Res 2009; 175: 151-161.

47. Bessero AC, Clarke PG. Neuroprotection for optic nerve disorders. Curr Opin Neurol 2010; 23: 10-15.

48. Harada C, Guo X, Namekata K, Kimura A, Nakamura K, Tanaka K et al. Glia- and neuronspecific functions of TrkB signalling during retinal degeneration and regeneration. Nat Commun 2011; 2: 189.

49. Chuang DM, Wang Z, Chiu CT. GSK-3 as a target for lithium-induced neuroprotection against excitotoxicity in neuronal cultures and animal models of ischemic stroke. Front $\mathrm{Mol}$ Neurosci 2011; 4: 15.

50. Hur EM, Zhou FQ. GSK3 signalling in neural development. Nat Rev Neurosci 2010; 11: 539-551.

51. Harada T, Harada C, Kohsaka S, Wada E, Yoshida K, Ohno S et al. Microglia-Müller glia cell interactions control neurotrophic factor production during light-induced retinal degeneration. J Neurosci 2002; 22: 9228-9236.
52. Katome T, Namekata K, Guo X, Semba K, Kittaka D, Kawamura K et al. Inhibition of ASK1 p38 pathway prevents neural cell death following optic nerve injury. Cell Death Differ 2013; 20: $270-280$.

53. Quigley HA. Glaucoma. Lancet 2011; 377: 1367-1377.

54. Resnikoff S, Pascolini D, Etya'ale D, Kocur I, Pararajasegaram R, Pokharel GP et al. Global data on visual impairment in the year 2002. Bull World Health Organ 2004; 82: 844-851.

55. Namekata K, Harada C, Kohyama K, Matsumoto Y, Harada T. Interleukin-1 stimulates glutamate uptake in glial cells by accelerating membrane trafficking of $\mathrm{Na}^{+} / \mathrm{K}^{+}$-ATPase via actin depolymerization. Mol Cell Biol 2008; 28: 3273-3280.

56. Harada T, Harada C, Watanabe M, Inoue Y, Sakagawa T, Nakayama N et al. Functions of the two glutamate transporters GLAST and GLT-1 in the retina. Proc Natl Acad Sci USA 1998; 95: 4663-4666.

57. Barres BA, Silverstein BE, Corey DP, Chun LL. Immunological, morphological, and electrophysiological variation among retinal ganglion cells purified by panning. Neuron 1988; 1: 791-803. 